\title{
Systematic investigations on the reduction of 4-aryl- 4-oxoesters to 1-aryl-1,4-butanediols with methanolic sodium borohydride
}

\author{
Subrata Kumar Chaudhuri ${ }^{1}$, Manabendra Saha ${ }^{2}$, Amit Saha ${ }^{3}$ \\ and Sanjay Bhar ${ }^{*}$
}

\section{Full Research Paper}

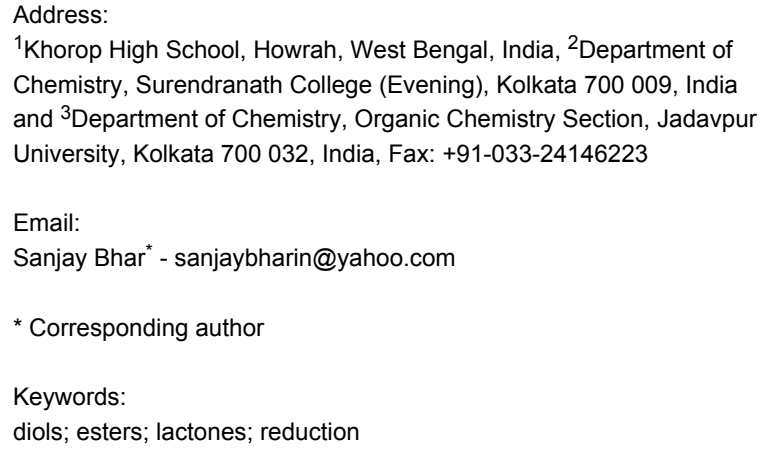

${ }^{1}$ Khorop High School, Howrah, West Bengal, India, ${ }^{2}$ Department of Chemistry, Surendranath College (Evening), Kolkata 700 009, India and ${ }^{3}$ Department of Chemistry, Organic Chemistry Section, Jadavpur University, Kolkata 700 032, India, Fax: +91-033-24146223

\begin{abstract}
4-Aryl-4-oxoesters undergo facile reduction of both the keto and the ester groups with methanolic $\mathrm{NaBH}_{4}$ at room temperature to yield the corresponding 1-aryl-1,4-butanediols whereas 4-alkyl-4-oxoesters furnish the corresponding 1,4-butanolides via selective reduction of the keto moiety. Results of a detailed and systematic investigation of the reaction are described.
\end{abstract}

\section{Introduction}

Chemoselective reductions of aldehydes, ketones and imines are generally accomplished using $\mathrm{NaBH}_{4}$ in methanol where other reducible functional groups, e.g. esters, nitro, nitriles, etc., remain unaffected [1-10]. Although it has been reported that some aliphatic and aromatic esters have been reduced with a large excess of sodium or other metal borohydrides [11,12], often in higher boiling solvents [13] and in combination with various additives $[14,15]$ including at a cationic micellar surface [16], selective reduction of the keto group in oxoesters has been accomplished using potassium borohydride in refluxing ethanol [17] where the product distribution critically depends on the relative proportions of substrate and reagent. Despite the occurrence of several recent reports of borohydride-mediated reduction of the ester moiety in $\alpha$-oxo- $[18,19]$ and $\beta$-oxoesters [20], sodium borohydride in various alcoholic solvents, often in the presence of additives [21], has been judiciously utilized [22] for the chemoselective reduction of the oxo-group, occasionally with subsequent transesterification and the formation of the alkoxy-modified $\beta$-hydroxyesters. $\gamma$-Oxoesters react chemoselectively with sodium borohydride to produce the corresponding $\gamma$-hydroxyesters [1,2,17,23-27] (sometimes in the form of $\gamma$-lactone) [24]. Following the above noted literature prece- 


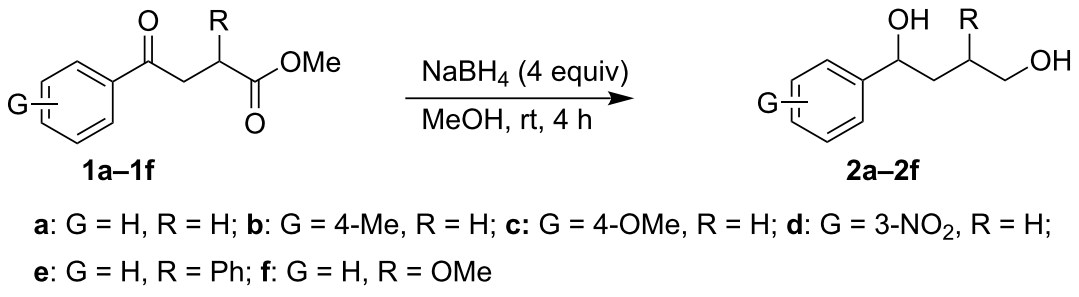

Scheme 1: Facile reduction of $\gamma$-aryl-y-ketoesters to the corresponding diols with methanolic $\mathrm{NaBH}_{4}$ at room temperature.

dences $[1,2,17,22-27]$ on the utility of $\mathrm{NaBH}_{4}$, we attempted to reduce 4-aryl-4-oxoesters with methanolic $\mathrm{NaBH}_{4}$ chemoselectively. Surprisingly, we found that 4-aryl-4-oxoesters underwent facile reduction of both the keto and the ester groups with methanolic $\mathrm{NaBH}_{4}$ at room temperature to yield the corresponding 1-aryl-1,4-butanediols whereas 4-alkyl-4-oxoesters furnished the corresponding 1,4-butanolides via selective reduction of the keto moiety. These results, to the best of our knowledge, have no literature precedence. We describe herein our systematic investigations to elucidate the different parameters involved in these reactions and to establish their synthetic usefulness.

\section{Results and Discussion}

When, the $\gamma$-aryl- $\gamma$-ketoesters $(\mathbf{1 a}-\mathbf{1 f})$ were treated with methanolic $\mathrm{NaBH}_{4}$ (4 equiv) at room temperature (room temperature implies $30{ }^{\circ} \mathrm{C}$ throughout) both the oxo- and the alkoxycarbonyl moieties were reduced to give the diols $(\mathbf{2 a}-\mathbf{2 f})$, as shown in Scheme 1.

$\gamma$-Aryl- $\alpha, \beta$-unsaturated- $\gamma$-ketoesters (1g and $\mathbf{1 h})$, on similar treatment, furnished the saturated diols ( $2 \mathbf{a}$ and $\mathbf{2 b}$ ) by the reduction of both the keto and the ester groups along with complete hydrogenation of the double bond (Scheme 2).

Detailed results are shown in Table 1.

At this point it is very interesting and important to note that only the oxo function of 4-alkyl-4-oxoester 3 was selectively reduced under the same conditions to yield lactone 4 without affecting the oxidation state of the alkoxycarbonyl moiety (Scheme 3).

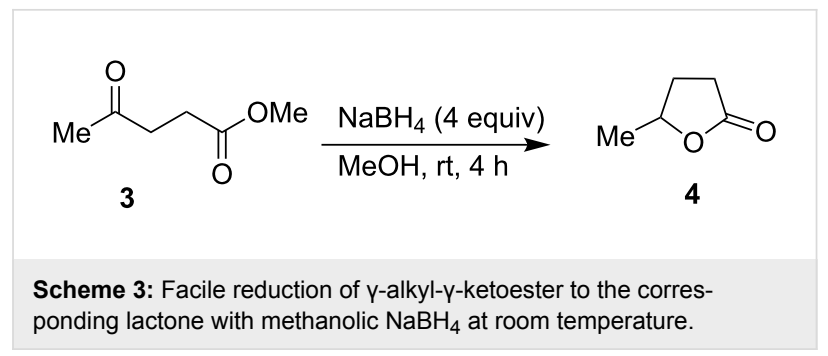

From the results obtained so far, it is obvious that $\mathrm{NaBH}_{4}$ in methanol can be efficiently used for the synthesis of 1-aryl-1,4butanediols from the easily accessible 4-aryl-4-oxoesters (Table 1) instead of employing the more costly and hazardous $\mathrm{LiAlH}_{4}$ which also often gives rise to several non-identifiable by-products. Structurally varied 1-aryl-1,4-butanediols are of great synthetic value with immense applications in cationic polymerizations [34], as intermediates for the syntheses of important acyclic antiviral nucleosides [35] and cyclic ethers [36].

Substrate 5 also underwent similar transformation under more drastic conditions to give a mixture of diol 6 [37] and lactone 7 [38], as shown in Scheme 4. In this instance no reaction took place at room temperature even after $24 \mathrm{~h}$ which might be ascribed to the lower electrophilicity of both the oxo- and alkoxycarbonyl functionalities of $\mathbf{5}$ from both electronic and steric standpoints.<smiles></smiles>

$1 \mathrm{~g}, 1 \mathrm{~h}$<smiles></smiles>

$2 a, 2 b$

$$
\text { g: } G=H ; h: G=4-M e
$$


Table 1: Reduction of 4-aryl-4-oxoesters (saturated and $\alpha, \beta$-unsaturated) with $\mathrm{NaBH}_{4}$ in $\mathrm{MeOH}$ at room temperature $\left(30{ }^{\circ} \mathrm{C}\right)$.

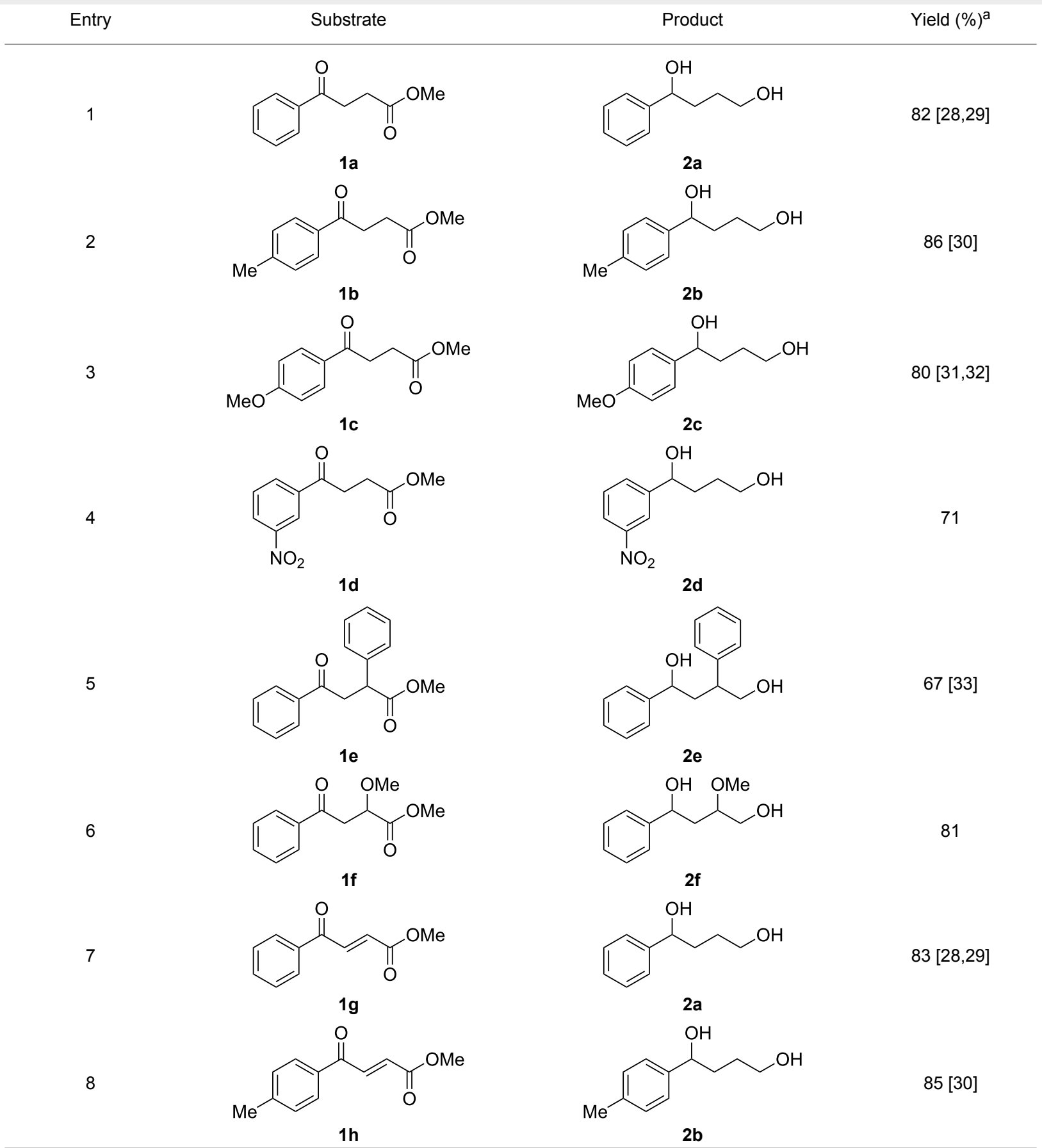

aYields refer to pure products, fully characterized spectroscopically $\left({ }^{1} \mathrm{H}\right.$ NMR, $\left.300 \mathrm{MHz}\right)$. References for known compounds are given in parenthesis after the respective yields.<smiles>COC(=O)c1ccccc1C(=O)c1ccccc1</smiles>

5

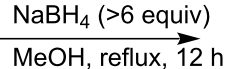

$\mathrm{MeOH}$, reflux, $12 \mathrm{~h}$<smiles>O=C1OC(c2ccccc2)c2ccccc21</smiles>

$(49: 51)$ 
The des-keto ester $\mathbf{8}$, as expected, was totally unaffected (Scheme 5) and was recovered unchanged.

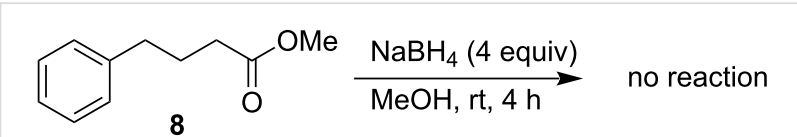

Scheme 5: Reluctance of ester 8 towards reduction with methanolic $\mathrm{NaBH}_{4}$ at room temperature.

Therefore, it is clear that the presence of both the aryl moiety and the oxo-function at the $\gamma$-carbon with respect to ester functionality is essential to bring about reduction of ester group with $\mathrm{NaBH}_{4}$. No reduction occurred when the reactions were carried out in anhydrous ether in place of methanol, however, substrates $\mathbf{1 a}$ and $\mathbf{1 b}$ in the ethereal medium underwent transformations in the presence of various protic polar co-solvents with different product distributions depending upon the nature of the co-solvent (Table 2).

Compounds 1a, $\mathbf{3}$, acetophenone and butyrophenone were individually subjected to reduction in ether (Table 3 ) in the presence of $\mathrm{MeOH}$ ( 2 equiv) for a limited period of time $(1 \mathrm{~h})$. It was observed that the reduction of the keto group in the $\gamma$-oxoesters 1a and 3 (entries 1 and 2 in Table 3) with the formation of the lactones $\mathbf{9}$ and $\mathbf{4}$ as one of the products was much faster than the reduction of aryl alkyl ketones (entries 3 and 4 in Table 3). Therefore, formation of lactone as the intermediate might be crucial for more facile reduction of the keto moiety in case of $\gamma$-oxoesters (entries 1 and 2 in Table 3), which is not possible in the case of normal aryl alkyl ketones (entries 3 and 4 in Table 3). It is also interesting to note that although in both $\mathbf{1 a}$ and 3 the keto group was completely reduced, the relative
Table 3: Comparative study ${ }^{\mathrm{a}}$ on reduction of various oxo-groups.

\begin{tabular}{|c|c|c|c|c|}
\hline \multirow[t]{3}{*}{ Entry } & \multirow[t]{3}{*}{ Substrate } & \multicolumn{3}{|c|}{ Relative proportion $(\%)^{\mathrm{b}}$ of } \\
\hline & & \multirow[t]{2}{*}{ Substrate } & \multicolumn{2}{|c|}{ Reduced products } \\
\hline & & & Lactone & $\begin{array}{c}\text { Y-Hydroxy } \\
\text { ester }\end{array}$ \\
\hline 1 & $1 \mathrm{a}$ & - & 62.5 & 37.5 \\
\hline 2 & 3 & - & 32.1 & 67.9 \\
\hline 3 & Acetophenone & 49.2 & \multicolumn{2}{|c|}{50.8} \\
\hline 4 & Butyrophenone & 61.0 & \multicolumn{2}{|c|}{39.0} \\
\hline
\end{tabular}

${ }^{a} \mathrm{NaBH}_{4}$ (4 equiv) in $\mathrm{Et}_{2} \mathrm{O}, \mathrm{MeOH}$ (2 equiv), $30^{\circ} \mathrm{C}, 1 \mathrm{~h}$. ${ }^{\mathrm{b}}$ Determined by $300 \mathrm{MHz}{ }^{1} \mathrm{H}$ NMR.

proportion of the lactone (compared to hydroxyester) was much higher for $\mathbf{1 a}$ than for $\mathbf{3}$.

The intermediacy of lactone 9 [24] was also established by an independent route as outlined in Scheme 6.

In order to prove the essentiality of the intermediacy of a lactone, compound $\mathbf{1 g}$ (with the keto and ester moieties kept far apart for lactonization due to trans-geometry of the olefinic linkage) was treated with $\mathrm{NaBH}_{4}$ (4 equiv) in methanol. However, this reaction unexpectedly led to the exclusive formation of 2a. With a smaller amount (2 equiv) of $\mathrm{NaBH}_{4}$ in methanol, compound $\mathbf{1 g}$ gave $\mathbf{9}$ and $\mathbf{2 a}$ in a ratio of 69:31(Scheme 7).

It was presumed that the formation of $\mathbf{2 a}$ from $\mathbf{1 g}$ might occur through the initial reduction of the keto group with the formation of the $\gamma$-hydroxy- $\gamma$-aryl- $\alpha, \beta$-unsaturated ester 10 [25]. In this connection it should be noted that when a limited amount of

Table 2: Reactions ${ }^{\mathrm{a}}$ of $\mathbf{1 a}$ and $\mathbf{1 b}$ with $\mathrm{NaBH}_{4}$ in anhydrous ether in the presence of protic polar co-solvents.

\begin{tabular}{|c|c|c|c|c|c|c|}
\hline \multirow[t]{2}{*}{ Entry } & \multirow[t]{2}{*}{ SM } & \multirow[t]{2}{*}{ Co-solvent } & \multicolumn{4}{|c|}{ Relative product distribution $(\%)^{\mathrm{b}}$} \\
\hline & & & Substrate & Lactone & Diol & Hydroxyester \\
\hline 1 & $1 a$ & $\mathrm{MeOH}$ & - & 37.1 & 62.9 & - \\
\hline 2 & $1 a$ & $\mathrm{EtOH}$ & - & 40.6 & 59.4 & - \\
\hline 3 & $1 a$ & $t-\mathrm{BuOH}$ & 5.8 & 94.2 & - & - \\
\hline 4 & $1 \mathrm{a}$ & $\mathrm{H}_{2} \mathrm{O}$ & 86.1 & 2.1 & 11.8 & - \\
\hline 5 & $1 a$ & $\mathrm{AcOH}$ & 87.3 & 3.1 & 9.6 & - \\
\hline 6 & $1 b$ & $\mathrm{MeOH}$ & - & Trace & 99.0 & - \\
\hline 7 & $1 b$ & $\mathrm{EtOH}$ & - & 48.2 & 51.8 & - \\
\hline 8 & $1 b$ & $t-\mathrm{BuOH}$ & 60.4 & 18.1 & - & 21.5 \\
\hline 9 & $1 b$ & $\mathrm{H}_{2} \mathrm{O}$ & 48.7 & 15.4 & - & 35.9 \\
\hline 10 & $1 b$ & $\mathrm{AcOH}$ & 21.9 & 51.4 & - & 26.6 \\
\hline
\end{tabular}

${ }^{\mathrm{a}} \mathrm{NaBH}_{4}$ (4 equiv) in $\mathrm{Et}_{2} \mathrm{O}$, co-solvent (2 equiv), $30{ }^{\circ} \mathrm{C}, 4$ h. ${ }^{\mathrm{b}}$ Determined by $300 \mathrm{MHz}{ }^{1} \mathrm{H} \mathrm{NMR}$. 


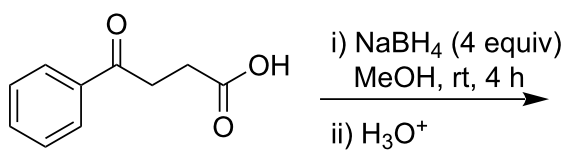

ii) $\mathrm{H}_{3} \mathrm{O}^{+}$<smiles>O=C1CCC(c2ccccc2)O1</smiles>

$\underset{\mathrm{MeOH}, \mathrm{rt}, 4 \mathrm{~h}}{\stackrel{\mathrm{NaBH}_{4} \text { (4 equiv) }}{\longrightarrow}}$<smiles>OCCCC(O)c1ccccc1</smiles>

$2 a$

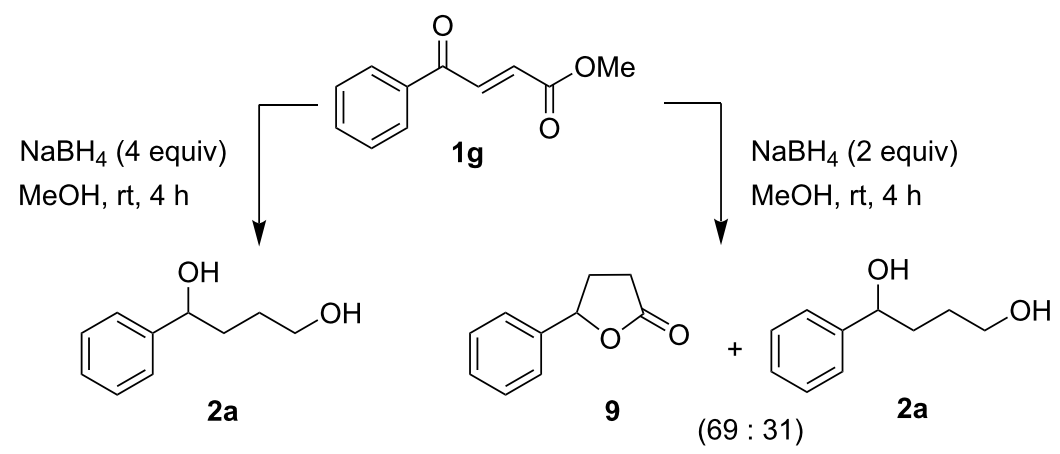

Scheme 7: Diol formation from $\gamma$-aryl- $\alpha, \beta$-unsaturated- $\gamma$-ketoester through the intermediacy of a saturated lactone during the reduction with methanolic $\mathrm{NaBH}_{4}$.

borohydride (1.2 equiv) was employed, we obtained the corresponding $\gamma$-hydroxy-trans- $\alpha, \beta$-enoic ester $\mathbf{1 0}$ from $\mathbf{1 g}$. $\gamma$-Hydroxy- $\alpha, \beta$-acetylenic esters have been reported [26] to undergo conjugate reduction of the triple bond with $\mathrm{NaBH}_{4}$ at low temperature $\left(-34{ }^{\circ} \mathrm{C}\right)$ to give the corresponding $\gamma$-hydroxy$\alpha, \beta$-alkenoic esters, where the conjugate reduction does not proceed beyond the double bond. However, we have observed conjugate reduction of $\gamma$-hydroxy- $\alpha, \beta$-alkenoic esters with methanolic $\mathrm{NaBH}_{4}$ (4 equiv) at $30{ }^{\circ} \mathrm{C}$ during the transformation of $\mathbf{1 0}$ to $\mathbf{2 a}$. Conjugate reduction here might be explained by the following plausible mechanistic scheme (Figure 1) where a mixed alkenyloxy alkoxy borohydride is initially formed by the reaction of $\mathbf{1 0}$ with sodium borohydride followed by conju- gate reduction of olefinic linkage by intramolecular hydride attack to produce saturated 4-hydroxyester, which subsequently cyclizes to yield $\mathbf{9}$ and then further reduced to the diol $\mathbf{2 a}$.

This postulate is supported by the observation that the proposed intermediate $\mathbf{1 0}$ (independently synthesized from 11) is reduced to $\mathbf{2 a}$ by the present method (Scheme 8 , dotted arrows denote the route proposed in Figure 1).

The fact that the reduction of the keto group occurs before the conjugate reduction of the olefinic linkage has also been established in this study. In the basic reaction medium produced by $\mathrm{NaBH}_{4}$, the $-\mathrm{COOH}$ group is converted to $-\mathrm{COO}^{-}$, and as a<smiles>COBOC(CC=C([O-])OC)c1ccccc1</smiles>
$n=1$ or 2<smiles>OCCCC(O)c1ccccc1</smiles><smiles>COC(C)(C)O</smiles><smiles>CCOC(=O)CCC(C)C</smiles>

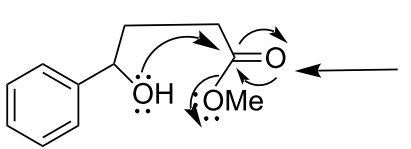<smiles>COC(=O)CCC(O)c1ccccc1</smiles>

Figure 1: Mechanistic rationale for diol formation during the reduction of a $\gamma$-aryl- $\alpha, \beta$-unsaturated- $\gamma$-ketoester with methanolic $\mathrm{NaBH}_{4}$. 


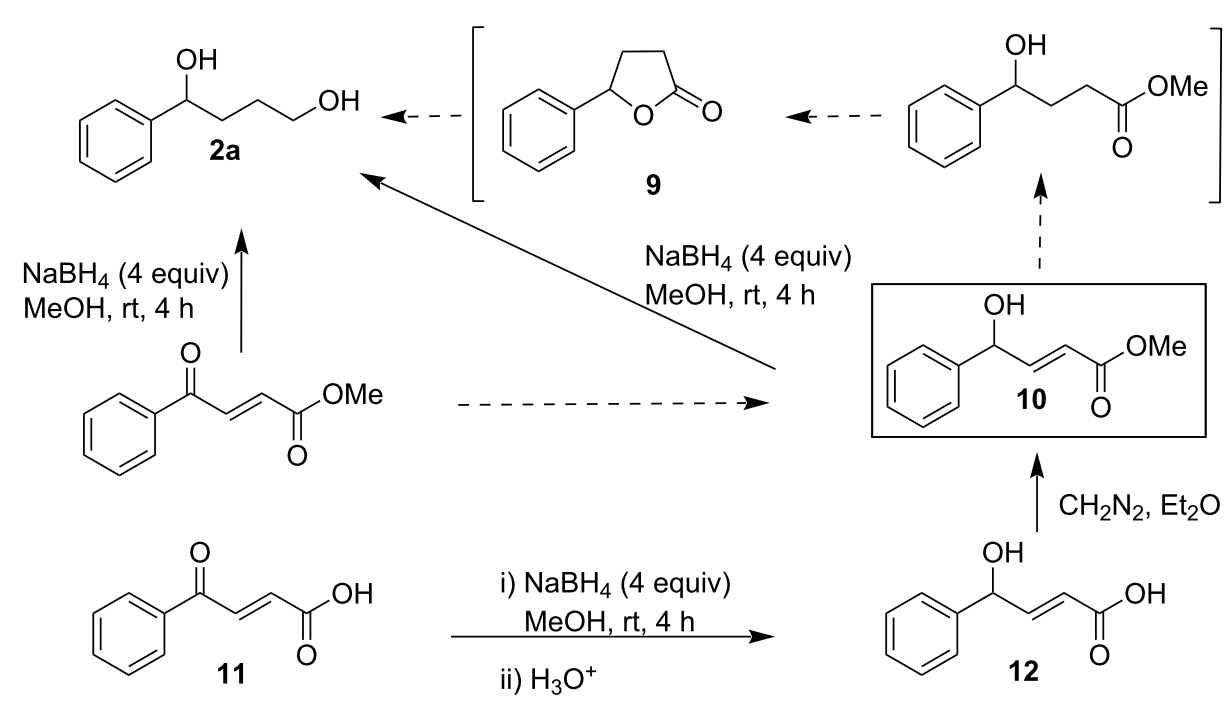

Scheme 8: Intermediacy of $\gamma$-aryl- $\alpha, \beta$-unsaturated- $\gamma$-hydroxyester during the reduction of $\gamma$-aryl- $\alpha, \beta$-unsaturated- $\gamma$-ketoesters with methanolic $\mathrm{NaBH}_{4}$

result the double bond is no longer electron-deficient. The conjugate reduction by the intramolecular nucleophilic attack of the hydride is therefore not feasible. As a consequence, the $-\mathrm{OH}$ and $-\mathrm{COO}^{-}$are too far apart to interact with each other. Therefore a single bond between the carbinol carbon and carboxylic acid moiety is impossible and hence no possibility of rotation, lactonization and subsequent reduction to diol 2a. For this reason the $\gamma$-keto- $\alpha, \beta$-enoic acid $\mathbf{1 1}$ on treatment with 4 equiv of $\mathrm{NaBH}_{4}$ in methanol smoothly furnished $\mathbf{1 2}$ as the preponderant product without conjugate reduction and subsequent reductive functional group transformation.

When substrate 13 [39] (with vicinal anti-dibromo substituents to increase the rotational barrier of the single bond) was reacted with methanolic $\mathrm{NaBH}_{4}$ (4 equiv) at room temperature, a mixture of 9, 10 and 2a was obtained in a ratio of 44:15:41 (as determined by $300 \mathrm{MHz}{ }^{1} \mathrm{H}$ NMR), as shown in Scheme 9.
Possibly, compound $\mathbf{1 3}$ was first reduced at the carbonyl function followed by concomitant dehydrobromination (under the basic reaction conditions), conjugate reduction at olefinic linkage, further dehydrobromination to $\mathbf{1 0}$ and subsequent conjugate reduction of $\mathbf{1 0}$ with the formation of $\mathbf{9}$ (as per the previous mechanistic scheme shown in Figure 1) and reduction of $\mathbf{9}$ to $\mathbf{2 a}$. The formation of $\mathbf{1 0}$ from $\mathbf{1 3}$ has been confirmed by the isolation of $\mathbf{1 0}$ (as the major product) as the outcome of the reaction of 13 with a limited amount of $\mathrm{NaBH}_{4}$ (1.5 equiv), as shown in Scheme 10.

The crucial role of the lactone formation during the borohydride-mediated reduction of 4-aryl-4-oxoester to 1,4-diols was finally established (Scheme 11) when substrate 14 [40] (incapable of lactonization due to distal spatial disposition of the oxo- and methoxycarbonyl moieties imposed by the rigidity of the cyclopropane ring system) underwent selective reduction of<smiles>COC(=O)/C=C/C(O)c1ccccc1</smiles>

$(44: 15: 41)$ 


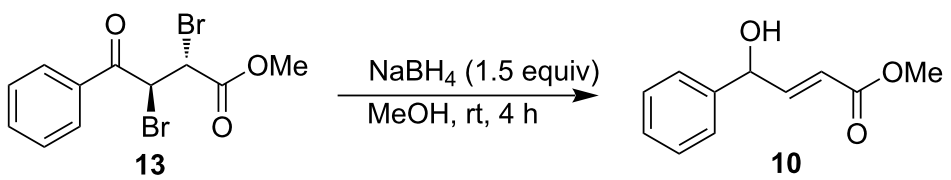

Scheme 10: Intermediacy of $\gamma$-aryl- $\alpha, \beta$-unsaturated- $\gamma$-hydroxyester during the reduction of $\gamma$-aryl- $\alpha, \beta$-anti-dibromo- $\gamma$-ketoester with methanolic $\mathrm{NaBH}_{4}$.<smiles>COC(=O)C1CC1C(=O)c1ccccc1</smiles>

Scheme 11: Chemoselective reduction of keto group in the presence of ester moiety where structural rigidity prevents the formation of a lactone intermediate during the reduction of $\mathrm{y}$-aryl- $\mathrm{y}$-ketoester with methanolic $\mathrm{NaBH}_{4}$.

the oxo-functionality only under refluxing conditions to yield 15. No significant reaction was observed at room temperature (monitored by TLC) even after $12 \mathrm{~h}$.

From the investigations carried out so far, the intermediacy of a lactone during the $\mathrm{NaBH}_{4}$-mediated facile reduction of saturated and $\alpha, \beta$-unsaturated- $\gamma$-aryl- $\gamma$-oxoesters to the corresponding saturated 1,4-butanediols has been firmly established. However, the reason for more facile reduction of the $\gamma$-aryllactones to diols and the relative reluctance of the $\gamma$-alkyl analogues is not yet clear.

\section{Conclusion}

From the above study, a novel method utilizing $\mathrm{NaBH}_{4}$ in methanol that can provide clean, cost-effective and facile access to differently substituted 1-aryl-1,4-butanediols in good yield and high purity from the easily accessible precursors has been developed. The results also indicate that caution should be exercised when methanolic sodium borohydride is used as a reagent $[1,2,17,22-27]$ for the chemoselective reduction of the keto group of all types of $\gamma$-oxoesters.

\section{Supporting Information}

General experimental procedure for the $\mathrm{NaBH}_{4}$ reduction and the spectral data of the products are presented as supplementary data.

\section{Supporting Information File 1}

Experimental.

[http://www.beilstein-journals.org/bjoc/content/ supplementary/1860-5397-6-94-S1.pdf]

\section{Acknowledgements}

The authors express sincere gratitude to Mr. N. Dutta of Indian Association for the Cultivation of Science, Kolkata, India for necessary assistance. Financial and infrastructural support from UGC-CAS programme in Chemistry, Jadavpur University, DST-PURSE programme and DST-FIST programme are also gratefully acknowledged.

\section{References}

1. Carey, F. A.; Sundberg, R. J. Advanced Organic Chemistry, 3rd ed.; Part A and Part B; Plenum Press: New York, 1990.

2. House, H. O. Modern Synthetic Reactions; Benjamin/Cummings Publishing Company: MA, 1972.

3. Kim, J.; Bruning, J.; Park, K. E.; Lee, D. J.; Singaram, B. Org. Lett. 2009, 11, 4358-4361. doi:10.1021/ol901677b

4. Alinezhad, H.; Tajbakhsh, M.; Zare, M. Synth. Commun. 2009, 39, 2907-2916. doi:10.1080/00397910802691882

5. Sawada, T.; Ishii, H.; Ueda, T.; Aoki, J. Synth. Commun. 2009, 39, 3912-3923. doi:10.1080/00397910902883546

6. Alinezhad, H.; Tajbakhsh, M.; Mahdavi, N. Synth. Commun. 2010, 40, 951-956. doi:10.1080/00397910903026731

7. Cook, C.; Guinchard, X.; Liron, F.; Roulland, E. Org. Lett. 2010, 12, 744-747. doi:10.1021/ol902829e

8. Watanabe, T.; Imaizumi, T.; Chinen, T.; Nagumo, Y.; Shibuya, M.; Usui, T.; Kanoh, N.; Iwabuchi, Y. Org. Lett. 2010, 12, 1040-1043. doi:10.1021/ol1000389

9. Mclver, A. L.; Deiters, A. Org. Lett. 2010, 12, 1288-1291. doi:10.1021/ol100177u

10. Collins, J.; Rinner, U.; Moser, M.; Hudlicky, T.; Ghiviriga, I.; Romero, A. E.; Kornienko, A.; Ma, D.; Griffin, C.; Pandey, S. J. Org. Chem. 2010, 75, 3069-3084. doi:10.1021/jo1003136

11. Brown, H. C.; Mead, E. J.; Subba Rao, B. C. J. Am. Chem. Soc. 1955, 77, 6209-6213. doi:10.1021/ja01628a044

12. Brown, M. S.; Rapoport, H. J. Org. Chem. 1963, 28, 3261-3263. doi:10.1021/jo01046a538

13. Soai, K.; Oyamada, H.; Ookawa, A. Synth. Commun. 1982, 12, 463-467. doi:10.1080/00397918208065953 
14. Yamakawa, T.; Masaki, M.; Nohira, H. Bull. Chem. Soc. Jpn. 1991, 64, 2730-2734. doi:10.1246/bcsj.64.2730

15. Bhanu Prasad, A. S.; Bhaskar Kanth, J. V.; Periasamy, M. Tetrahedron 1992, 48, 4623-4628. doi:10.1016/S0040-4020(01)81236-9

16. Das, D.; Roy, S.; Das, P. K. Org. Lett. 2004, 6, 4133-4136. doi:10.1021/ol0481176

17. Barnett, J. E. G.; Kent, P. W. J. Chem. Soc. 1963, 2743-2747. doi:10.1039/JR9630002743

18. Dalla, V.; Cotelle, P.; Catteau, J. P. Tetrahedron Lett. 1997, 38, 1577-1580. doi:10.1016/S0040-4039(97)00154-8

19. Dalla, V.; Catteau, J. P.; Pale, P. Tetrahedron Lett. 1999, 40, 5193-5196. doi:10.1016/S0040-4039(99)01006-0

20. Soai, K.; Oyamada, H. Synthesis 1984, 605-607. doi:10.1055/s-1984-30911

21. Taniguchi, M.; Fujii, H.; Oshima, K.; Utimoto, K. Tetrahedron 1993, 49, 11169-11182. doi:10.1016/S0040-4020(01)81804-4

22. Padhi, S. K.; Chadha, A. Synlett 2003, 639-642. doi:10.1055/s-2003-38366

23. Nozaki, H.; Kondô, K.; Nakanisi, O.; Sisido, K. Tetrahedron 1963, 19 , 1617-1623. doi:10.1016/S0040-4020(01)99236-1

24. Karnik, A. V.; Patil, S. T.; Patnekar, S. S.; Semwal, A. New J. Chem. 2004, 28, 1420-1422. doi:10.1039/b409061f

25. Naka, T.; Koide, K. Tetrahedron Lett. 2003, 44, 443-445. doi:10.1016/S0040-4039(02)02602-3

26. Meta, C. T.; Koide, K. Org. Lett. 2004, 6, 1785-1787. doi:10.1021/ol0495366

27. Ward, R. S. Selectivity in Organic Synthesis; John Wiley and Sons: West Sussex, England, 1999; pp 4 ff.

28. Mori, N.; Ōmura, S.; Tsuzuki, Y. Bull. Chem. Soc. Jpn. 1965, 38 1631-1634. doi:10.1246/bcsj.38.1631

29. Tanner, D.; Groth, T. Tetrahedron 1997, 53, 16139-16146. doi:10.1016/S0040-4020(97)10053-9

30. Bhat, K. S.; Rao, A. S. Indian J. Chem. 1981, 20B, 355-358.

31. Mudryk, B.; Cohen, T. J. Org. Chem. 1989, 54, 5657-5659. doi:10.1021/j000285a008

32. Kamal, A.; Sandbhor, M.; Shaik, A. A. Tetrahedron: Asymmetry 2003, 14, 1575-1580. doi:10.1016/S0957-4166(03)00281-7

33. Gurudutt, K. N.; Pasha, M. A.; Ravindranath, B.; Srinivas, P. Tetrahedron 1984, 40, 1629-1632. doi:10.1016/S0040-4020(01)91816-2

34. Azuma, N.; Sanda, F.; Takata, T.; Endo, T. Macromolecules 1998, 31, 1710-1715. doi:10.1021/ma971082n

35. Mullah, K. B.; Bentrude, W. G. J. Org. Chem. 1991, 56, 7218-7224. doi:10.1021/jo00026a008

36. Shibata, T.; Fujiwara, R.; Ueno, Y. Synlett 2005, 152-154. doi:10.1055/s-2004-835664

37. Kirmse, W.; Kund, K. J. Org. Chem. 1990, 55, 2325-2332. doi:10.1021/jo00295a018

38. Newman, M. S. J. Org. Chem. 1961, 26, 2630-2633. doi:10.1021/jo01066a004

39. Chaudhuri, S. K.; Roy, S.; Saha, M.; Bhar, S. Synth. Commun. 2007, 37, 271-274. doi:10.1080/00397910601033617

40. Papageorgiou, C. D.; Ley, S. V.; Gaunt, M. J. Angew. Chem., Int. Ed. Engl. 2003, 42, 828-831. doi:10.1002/anie.200390222

\section{License and Terms}

This is an Open Access article under the terms of the Creative Commons Attribution License

(http://creativecommons.org/licenses/by/2.0), which permits unrestricted use, distribution, and reproduction in any medium, provided the original work is properly cited.

The license is subject to the Beilstein Journal of Organic Chemistry terms and conditions:

(http://www.beilstein-journals.org/bjoc)

The definitive version of this article is the electronic one which can be found at:

doi:10.3762/bjoc.6.94 